\title{
UMA CONFIGURAÇÃO PARA O ENSINO SECUNDÁRIO (1930-1960): CULTURA, FORMAÇÃO HUMANA E BOA EDUCAÇÃ̃O
}

\author{
DOI: http://dx.doi.org/10.1590/2236-3459/64137
}

Fabiany de Cássia Tavares Silva

Maurinice Evaristo Wenceslau

Universidade Federal de Mato Grosso do Sul (UFMS), Campo Grande/Mato Grosso do Sul, Brasil

\section{$\cos 80$}

\begin{abstract}
Resumo
Neste texto apresentamos alguns resultados de pesquisa, inscrita no campo da história da educação, circunscrita ao cruzamento dos campos da história política-jurídica e do pensamento curricular, que mapeou uma configuração do ensino secundário nos discursos projetados sobre as noções de cultura, formação humana e boa educação. Tal projeção tomou como fontes um conjunto de dissertações e teses produzidas sobre o ensino secundário pelos/nos Grupos de Estudos e Pesquisas, Observatório de Cultura Escolar (UFMS) e História da Educação (UFMG), no período de 1999 a 2010. Tais fontes são tomadas na perspectiva de investigar comparativamente como foram tratados, observados e/ou analisados documentos oficias (Leis, Decretos, Portarias, entre outros) do ensino secundário, publicados no período de 1930 a 1960. Neste enquadramento, essa investigação está ancorada na hipótese de que os estudos sobre ensino secundário, produzidos pelas dissertações e teses, em comparação, de um lado, registram processos de relativização cultural e ideológica, promotoras de novas formas de entender a apropriação dos documentos legais nacionais e locais. De outro, demonstram a necessidade de desmistificação das noções de cultura, formação humana e consciência patriótica que, quando transpostas para os documentos, parecem apenas uma versão singular fundada no processo de "universalização" deste nível de ensino.

Palavras-chave: história do ensino secundário, história político-jurídica, estudos curriculares.
\end{abstract}

\section{A CONFIGURATION FOR SECONDARY EDUCATION (1930-1960): CULTURE, HUMAN FORMATION AND GOOD EDUCATION}

\begin{abstract}
In this text we present some results of research, inscribed in the field of history of education, limited to the crossing of the fields of political and judicial history and the curricular thought, which sought to map a secondary school configuration in speeches, projected on the notions of culture, human formation and good education. This projection has taken as sources a set of dissertations produced on secondary education by / in the Studies and Research Groups, School Culture Observatory (UFMS) and History of Education (UFMG), in the period from 1999 to 2010. Such sources are taken in the perspective to comparatively investigate how official documents of secondary education (Laws, Decrees, Ordinances and others), published from 1930 to 1960 , were treated, observed and/or analyzed. In this framework, this research is anchored on the hypothesis that the studies on secondary education, produced by the dissertations and theses, in comparison, on the one hand, can register processes of cultural and ideological relativism promoting new ways of understanding the
\end{abstract}


appropriation of the national and local legal documents. On the other hand, by the need to demystify the notions of culture, human formation and patriotic consciousness that, when incorporated into the documents, seem to be just a singular version founded in the process of "universalization" of this level of education.

Keywords: history of secondary education, political and judicial History, curriculum studies.

\title{
UNA CONFIGURACIÓN PARA LA ENSEÑANZA SECUNDARIA (1930-1960): CULTURA, FORMACIÓN HUMANA Y BUENA EDUCACIÓN
}

\section{Resumen}

En este texto presentamos algunos resultados de investigación inscrita en el campo de la historia de la educación, circunscrita al cruce de los campos de la historia política-jurídica y del pensamiento curricular, que planteó mapear una configuración de la enseñanza secundaria en los discursos proyectados sobre las nociones de cultura, formación humana y buena educación. Esta proyección ha tomado como fuentes un conjunto de disertaciones producidas sobre la enseñanza secundaria por los/en los Grupos de Estudios e Investigaciones, Observatorio de Cultura Escolar (UFMS) e Historia de la Educación (UFMG), en el período de 1999 a 2010. Dichas fuentes se tomaron en la perspectiva de investigar comparativamente como fueron tratados, observados y/o analizados documentos oficiales (Leyes, Decretos, Órdenes Ministeriales, entre otros) de la enseñanza secundaria, publicados entre 1930 y 1960. En este contexto, la investigación está anclada en la hipótesis de que los estudios sobre enseñanza secundaria producidos por las disertaciones y tesis, en comparación, por una parte, pueden registrar procesos de relativización cultural e ideológica, promotoras de nuevas formas de entender la apropiación de los documentos legales nacionales y locales. Por otra, presentan la necesidad de desmitificación de las nociones de cultura, formación humana y consciencia patriótica que, cuando transpuestas para los documentos, parecen simplemente una versión singular fundada en el proceso de "universalización" de este nivel de enseñanza.

Palabras clave: historia de la enseñanza secundaria, historia político-jurídica, estudios curriculares.

\section{UNE CONFIGURATION DE L'ENSEIGNEMENT SECONDAIRE (1930-1960): LA CULTURE, LE DÉVELOPPEMENT HUMAIN ET UNE BONNE ÉDUCATION}

\begin{abstract}
Résumé
Dans cet article, nous présentons quelques résultats de recherche enregistrés dans le domaine de l'histoire de l'éducation, limité à l'intersection des domaines de l'histoire politique-juridique et curriculaire pensée, qui a soulevé la carte une configuration de l'enseignement secondaire dans les discours projeté sur les notions de culture, le développement humain et une bonne éducation. Cette projection a pris comme sources un ensemble de dissertations produites sur l'enseignement secondaire par / dans le Groupe d'étude et de recherche de la Culture School (UFMS) et Histoire de l'éducation (UFMG), dans la période 1999-2010. Ces sources ont été prises en vue de relativement étudier comment ils ont été traités, observés et / ou analysé les documents officiels (lois, décrets, arrêtés ministériels, etc.) de l'enseignement secondaire, publiés entre 1930 et 1960. Dans ce contexte, la recherche est ancré sur l'hypothèse que les études de l'enseignement secondaire produit par dissertations et thèses, en comparaison, d'une part, peuvent enregistrer les processus de relativisme culturel et idéologique, la promotion de nouvelles façons de comprendre l'appropriation des documents juridiques nationaux et locaux. En outre, ils présentent la nécessité de démystification des notions de culture, la formation humaine et de la conscience patriotique qui, lorsqu'elle est transposée aux documents, il suffit de regarder comme une version unique basé sur le processus de la «mondialisation» de ce niveau d'enseignement.

Mots-clés: histoire de l'enseignement secondaire, l'histoire politique et juridique, étude du curriculum.
\end{abstract}




\section{Notas introdutórias}

$\mathrm{N}$

este texto apresentamos alguns resultados de pesquisa ${ }^{1}$, inscrita no campo da história da educação, circunscrita ao cruzamento dos campos da história política-jurídica e do pensamento curricular, que apreende um sentido de configuração para o ensino secundário nos discursos projetados sobre as noções de cultura, formação humana e boa educação.

O sentido de configuração ${ }^{2}$ delineia-se na perspectiva de que por ser social, a configuração é sempre um espaço de síntese, provisória, do movimento dialético da realidade. Dessa forma, não se trata de reconstruir um "outro ensino secundário", mas a dar lugar ao "outro do próprio ensino secundário".

Neste sentido, esta investigação está ancorada na hipótese de que:

[...] os estudos sobre ensino secundário, em comparação, de um lado, podem registrar processos de relativização cultural e ideológica promotoras de novas formas de entender a apropriação dos documentos legais nacionais e locais. De outro, pela necessidade de desmistificação das noções de cultura, formação humana e consciência patriótica que, quando transpostas para os documentos, parecem apenas uma versão singular fundada no processo de "universalização" deste nível de ensino. (SILVA, 2013, p. 7).

O conjunto dos interesses, das crenças morais, religiosas e das posições sociais, provavelmente, estabelece diferentes princípios para o contrato educativo justo, ou mesmo para se alcançar a justiça, pois o ensino secundário parece fundar-se no princípio da meritocracia.

Com inspiração nesses princípios, ao ensino secundário, em tese, parece ter sido delegado o poder de preparar o conjunto de uma faixa etária e assegurar uma repartição mais democrática das posições profissionais e hierárquicas na sociedade. Em conformidade com essa tese, o ensino secundário justo e democrático, buscaria cumprir o seu papel, ao oferecer uma formação moral a todos os indivíduos indistintamente, proporcionando meios para constituírem-se como cidadãos capazes. Contudo, os critérios de seleção dos alunos para a entrada neste nível de ensino incorporam a premissa de educar os mais capazes, ao estabelecer exames de seleção, ao mesmo tempo, que o Estado ao reconhecer o direito à educação de todos, no entanto, impôs uma barreira camuflada pela ideia da elitização, do aproveitamento e da preparação dos dirigentes.

A par disso, tomamos como fontes, para as análises aqui pretendidas, um conjunto de dissertações e teses ${ }^{3}$ produzidas sobre o ensino secundário pelos/nos Grupos de Estudos e Pesquisas, Observatório de Cultura Escolar (OCE, UFMS) e História da Educação (GEPHE, UFMG), no período de 1999 a 2012. Tais fontes permitem investigar comparadamente a apropriação dos documentos oficias (Leis, Decretos, Portarias, entre outros) do ensino secundário, publicados no período de 1930 a 1960, na escrita dessas histórias acerca/sobre/do ensino secundário.

\footnotetext{
${ }^{1}$ Observatório de Cultura Escolar (9): estudo histórico-comparado da produção de conhecimento sobre o Ensino Secundário. (SILVA, 2013).

2 O conceito de configuração "serve como instrumento conceitual para modificar a visão antagônica e contraposta de indivíduo e sociedade; deve ser entendido como um padrão mutável no jogo das relações, cuja interdependência entre os atores sociais, forma um entrelaçamento flexível e com tensões". (ELIAS, 1980, p. 142).

3 Composto de seis dissertações e uma tese do GEPHE e, oito dissertações do OCE.
} 
Para tanto, recuperamos a premissa defendida por Depaepe \& $\operatorname{Simon}^{4}$ segundo a qual "não é a fonte o que se encontra no início da operação historiográfica e, sim, as interrogações que se colocam à investigação e são essas decisivas para a utilização das fontes". (2010, p. 102, tradução nossa).

Dando forma a esta premissa e apoiados na configuração apresentada interrogamos um modelo para ensino secundário, que tanto sofre como assume ações que denotam equilíbrio de poder mais ou menos instáveis, dependendo da cultura da qual fazem parte. Diante disso, estabelecemos como áreas de comparação, a cultura, a formação humana e a boa educação. Vale ressaltar, que as áreas de comparação são procedimentos investigativos, construídos por

[...] percursos teórico-metodológicos do estudo comparado, que entendemos uma versão particular, por recorrermos ao cruzamento da educação comparada com a história comparada, esta última investigada pelos referentes do método histórico, que tem nos permitido buscar as diferenças e semelhanças do/no particular a partir dos processos históricos mais amplos (compreender a história como processo) e, reconstruí-las como parte de uma determinada realidade que é sempre complexa e aberta às transformações sob a ação dos sujeitos sociais (utilizando a história como método). (SILVA, 2016, p. 4, grifos nossos).

No caso deste estudo, as áreas de comparação estão submetidas a uma significação mais larga, que procura entender os mecanismos de constituição do discurso expresso na pauta de um ensino mais justo, não "porque reduziu a diferença quanto aos resultados favoráveis entre as categorias sociais e, sim, porque permitiu que todos os alunos entrassem na mesma competição". (DUBET, 2004, p. 541).

Assim, os discursos criam uma concorrência discursiva e posicional, abstraindo-a da relação entre os estudos histórico-jurídicos e do pensamento curricular, por meio de um conjunto organizado de significados e práticas relacionado a um processo de valoração das ações, que devem ser vividas no e pelo acesso ao conhecimento.

\section{Uma história já escrita do ensino secundário brasileiro}

Na historiografia sobre o ensino secundário brasileiro, anteriores à década de 1930, é comum referências às reformas sofridas desde 1837, após a criação do Imperial Collegio de Pedro, entre elas destacam-se as Reformas Benjamim Constant (Decreto 981,1890), pela qual o ensino secundário começou a ser republicanizado; Epitácio Pessoa (Decreto 3890, 1901), que de um lado, alterou o currículo do ensino secundário ao incluir a lógica entre as matérias, retirando a Biologia, a Sociologia e a Moral, acentuando, assim, a parte literária em detrimento da científica; e, de outro, propôs o curso secundário como um mero curso preparatório para ingresso nas Faculdades existentes na época, reduzindo-o para seis anos; Rivadávia Correa (Decreto 8659, 1911) atribuindo ao ensino o caráter de frequência não obrigatória, abolindo os diplomas e, criando os exames de admissão às Faculdades (uma espécie de vestibular), que seriam realizados nas próprias instituições de ingresso dos candidatos; Carlos Maximiliano (Decreto 11.530, 1915), que reoficializou o ensino no Brasil; e Rocha Vaz (Decreto 16782 A, 1925), que reconheceu o curso secundário

\footnotetext{
4 "[...] no es la fuente lo que se encuentra en el inicio de la operación historiográfica sino el/los interrogante/es que se plantean en la investigación y son estos interrogantes los decisivos para la utilización de las fuentes". (DEPAEPE; SIMON, 2010, p. 102).
} 
como curso regular, definindo seis anos seriados de estudos, com o intuito de oferecer um preparo geral e fundamental para a vida.

Já entre os anos de 1930 a 1960, destaca-se o impacto das reformas empreendidas pelo ministro Francisco Campos (Decretos no 19.890 de 18 de abril de 1931 e no 21.241 de 4 de abril de 1932) na organização (currículo, disciplinas e habilitações) e no funcionamento (cursos preparatórios, exames parcelados, frequência obrigatória), visando à formação e modernização deste nível de escolarização.

Tais reformas estão no bojo do processo pelo qual o Brasil inicia a reorientação de suas bases econômicas, políticas e sociais, marcadas pela idealização de um modelo voltado à industrialização, centralização administrativa, urbanização e construção de um projeto nacionalista.

Segundo Schwartzman, Bomeny e Costa (2000), esse projeto visa à formação do novo homem, em conformidade com as exigências de uma sociedade urbano-industrial, que seria implantada, sendo necessária a homogeneização cultural, linguística, ideológica e de costumes.

Neste contexto, somente com a publicação do decreto $n^{0} 4.244$ de 09 de abril de 1942, Lei Orgânica do Ensino Secundário, ou Reforma Capanema, se atribui a este nível de ensino sua finalidade fundamental, "formar, em prosseguimento da obra educativa do ensino primário, a personalidade integral dos adolescentes; acentuar e elevar, na formação espiritual dos adolescentes, a consciência patriótica e a consciência humanística e; dar preparação intelectual geral que possa servir de base a estudos mais elevados de formação especial".

Para Souza (2008), a Reforma Capanema retoma o predomínio da formação humanista desinteressada, "destinada à formação de uma cultura enciclopédica, representando assim uma vitória dos setores conservadores da sociedade e o rompimento com o tênue equilíbrio entre estes e os renovadores, característico da Reforma Francisco Campos" (p. 172).

Em que pese o teor reformista deste conjunto legal, as transformações propostas não modificam substancialmente as escolas do ensino secundário. E entre o período de 1946 a 1961, a atuação do governo federal limita-se a iniciativas pontuais ${ }^{5}$, enquanto se debate no Congresso o projeto da Lei de Diretrizes e Bases da Educação Nacional (LDB).

A LDB n. 4024, de 1961, incrementa a flexibilização do currículo por meio da indicação das disciplinas obrigatórias e daquelas que devem ser optativas, ou complementares, o que indica o predomínio das áreas científicas e técnicas, em detrimento das humanidades. Em meio a isso, reorienta o controle que o governo central exerce sobre o ensino secundário, atendendo aos interesses daqueles que advogam pela descentralização do sistema de ensino.

Após 1964, com a ditadura civil-militar inicia-se o processo de redefinição da política educacional em todos os níveis, destinando ao Ministério do Planejamento o poder de

\footnotetext{
5 Criação dos chamados programas mínimos de conteúdos, que foram executados por meio da Portaria $\mathrm{n}$. 1.045 de dezembro de 1951. Na sequência deu-se a criação da Campanha de Aperfeiçoamento e Difusão do Ensino Secundário (Cades), em 1953 e a criação do Fundo Nacional do Ensino Médio, em 1954; a promulgação das Leis de Equivalência, 1.076/50, 1.821/53 e 3.104/57, que buscou "articulação do ensino secundário aos demais ramos, permitindo aos estudantes a transferência de um ramo ao outro ou de um ciclo a outro, mediante exames de adaptação ou complementação". (NUNES, 2000, p. 53).
} 
decisão nas matérias de educação, dando forma às reformas pedagógicas previstas nos planos de reorientação do modelo político-econômico.

A premissa básica deste modelo de organização fortalece a dualidade no processo de formação do ensino secundário, ora destinado a preparar as elites governantes, ora os trabalhadores para a indústria.

Neste quadro, torna-se necessário compreender a história deste nível de ensino, reconhecendo a originalidade da produção dos saberes sobre/nas/das fontes eleitas, na perspectiva de que as mudanças desses saberes estão ligadas a muito mais, do que as mudanças sociais e políticas de um país, neste caso, ao desenvolvimento de duas regiões, o sul do Mato Grosso ${ }^{6}$ e Minas Gerais. Para tanto, configura-se uma cultura escolar, conjunto de práticas, normas, ideias e procedimentos, que se expressam em modos de fazer e pensar o cotidiano da escola secundária em duas cidades expressivas destas regiões, Campo Grande e Belo Horizonte.

\section{Sobre a comparação na operação historiográfica}

O reaparecimento dos estudos comparados no meio acadêmico e nas pesquisas em Educação, na última década do século $X X$, com diferentes propósitos e alinhamentos teórico-metodológicos, tem nos levado a interrogações desde a produção de generalizações e singularidades, na perspectiva da melhoria dos sistemas educativos, até o privilegiamento de dados estruturais. (SILVA, 2014).

No atual contexto, a perspectiva parece incidir sobre diferentes unidades e objetos, determinadas pela cultura e o discurso, transformando-se em argumento explanatório na medida em que consegue identificar por meio de reconstruções conceitualmente informadas, soluções de problemas historicamente realizados como realizações particulares daquilo que nos diferentes cenários, ou configurações socioculturais é estruturalmente possível.

Diante disso, a realidade educacional em comparação leva à descoberta de regularidades, percepção de deslocamentos e transformações, construção de modelos e tipologias, identificação de continuidades e descontinuidades, semelhanças e diferenças, explicitando determinações mais gerais que regem os fenômenos sociais. Determinações essas que perpassam à ampliação dos conhecimentos acerca das teorias e técnicas da comparação, a partir da crítica ao que está apontado como ausente nas eleições das "ferramentas analíticas, incluindo noções de transferência, adaptação, hibridismo e tradução, que também são produtos da história, e as variáveis independentes que não podemos importar, sem dúvida, para organizar histórias sobre o passado."7 (FENDLER, 2013, p. 225, tradução nossa).

Se tomarmos a cultura, no campo histórico-jurídico, ela será apresentada como possibilidade da unidade do homem, respeitando suas diversidades quanto ao modo de

\footnotetext{
${ }^{6}$ Essa porção do estado de Mato Grosso era constituída pelas cidades: "Corumbá, Miranda, Santana do Paranaíba, Nioaque, Coxim, Campo Grande, Aquidauana e Bela Vista; esses municípios são aqueles que depois, desmembrados em vários outros, viriam a constituir o estado de Mato Grosso do Sul". (QUEIROZ, 1997, p. 115-116).

7 [...] analytical tools-including notions of transfer, adaptation, hybridity, and translation-are also products of history, and not independent variables that we can import without question to organize stories about the past. (2013, p. 225).
} 
vida e de crença, isto é, a aculturação. Contudo, a aculturação aparece não como um fenômeno ocasional, de feitos devastadores, mas como uma das modalidades habituais da evolução cultural de cada sociedade. Já no campo do pensamento curricular, a cultura perpassa todas as ações do cotidiano escolar, seja na influência sobre os seus ritos ou sobre a sua linguagem, seja na determinação das suas formas de organização e de gestão, seja na constituição dos projetos curriculares, desde o estudo sobre as disciplinas chegando às culturas escolares.

Neste contexto, segundo Warde (2013), alguns autores oferecem elementos para a construção de conceitos, ou mesmo, práticas de pesquisa, a saber:

Chervel parecia afirmá-la de maneira mais contundente como original e se interessava principalmente pela construção dos saberes escolares; Julia fazia a ênfase da análise recair particularmente sobre as práticas escolares, o que o levava a distinguir entre uma cultura escolar primária e uma cultura escolar secundária; Forquin parece que procurava juntar duas tendências pensando a cultura escolar como ao mesmo derivada e como original e; Antonio Viñao Frago dirá em seus primeiros textos sobre cultura escolar: é tudo o que se passa dentro da escola. (WARDE, 2013, p. 41).

Essa constatação faz com que percebamos que as possibilidades de investigações estão voltadas para a procura de caminhos tanto no sentido da construção do próprio conceito de cultura escolar na perspectiva de que tome a solidez e a elasticidade capazes de abrigar a complexidade das práticas sociais e dos sentidos da escola.

No tocante à formação humana, está delineada pela perspectiva da cidadania, qual seja, o estatuto que rege, de um lado, o respeito e a obediência que o cidadão deve ao Estado e, de outro lado, a proteção e os serviços que o Estado deve dispensar, pelos meios possíveis, ao cidadão. Em se tratando do pensamento curricular, a preocupação com a função da formação humana foge de uma concepção utilitarista e liberal, pois é parte da concepção da escolarização justa, que se esforça por garantir a igualdade individual de oportunidades.

Em relação à boa educação, em um campo é considerada um bem primário ${ }^{8}$ (RAWLS, 2002), pois é presumível que um sujeito racional a deseje, não importando o que mais ele deseje. Uma vez que dela depende a compreensão da organização estatal, dos direitos e garantias individuais, valores culturais, bem como das obrigações e das consequências de seus atos. No outro, processo de interiorização de conteúdos do ensino, que são produtos de uma seleção realizada no seio da cultura, o que significa que não se ensina tudo o que compõe uma cultura, e que toda educação realiza uma combinação particular de ênfases e de omissões.

Neste sentido, tentar perceber essas áreas, em diferentes histórias de ensino secundário, na perspectiva da configuração de um "outro do próprio ensino secundário", leva-nos, também, a perscrutar os limites das apropriações.

\footnotetext{
8 [...] os direitos e liberdades básicos - liberdades civis e políticas; liberdade de circulação e escolha; oportunidades; riqueza, rendimento; poderes e prerrogativas de cargos e posições de responsabilidade nas instituições políticas e econômicas da estrutura básica; e as bases sociais do respeito próprio -, as pessoas acreditam realizar seus planos de vida, pois "são bens indispensáveis à realização, pelo ser humano, de sua personalidade moral, cuja reivindicação é justificada". (RAWLS, 2002, p. 302).
} 


\section{Uma configuração para o ensino secundário na escrita sobre a cultura, a formação humana e a boa educação}

Aqui operamos apenas com o estudo de 4 dissertações, sendo duas do OCE e duas do GEPHE, tomadas como fontes escritas, utilizando como critério de seleção, a proximidade dos estudos pretendidos, qual seja, momentos históricos distintos da organização deste nível de ensino, Era Vargas e República Nova, suas instituições escolares e a organização do currículo, particularmente, a proposição de disciplinas escolares.

As dissertações escolhidas são: Braga (OCE, 2005), que pretendeu escrever uma história do ensino do Latim, como disciplina integrante do currículo do curso ginasial, no período compreendido entre 1938 e 1971, tendo como locus histórico e social a Escola Estadual Maria Constança Barros Machado; Neiva (GEPHE, 2008), que investigou a implantação e a consolidação do Canto Orfeônico enquanto modalidade de educação musical na Escola Normal de Belo Horizonte, atual Instituto de Educação de Minas Gerais, no período compreendido entre 1934 e 1971; Oliveira (OCE, 2009), que estudou a história da disciplina escolar de Francês pelo seu funcionamento no curso ginasial do Colégio Estadual Campo-grandense, em Campo Grande, na época, Estado de Mato Grosso, entre 1942 e 1962; e Santos (GEPHE, 2010), que estudou duas instituições particulares de ensino constituídas por missionários estrangeiros, alemães e norte-americanos, na cidade de Belo Horizonte, durante a primeira metade do século XX (1900-1950).

Cabe ressaltar, que não utilizamos essas fontes na perspectiva de análise e/ou avaliação dos exercícios teórico-metodológicos realizados, tampouco dos questionamentos acerca das fontes eleitas/acessadas para a escrita da história do ensino secundário, estamos, sim, interessados na história informada/construída, para alimentar o debate com a hipótese que elaboramos.

O conjunto dessas dissertações estabelece como premissa para a construção histórico-analítica deste nível de ensino, o uso da legislação (Leis, Decretos, Decretos-Leis, Portarias, entre outros), que de alguma forma informou, instituiu, possibilitou a operacionalização em diferentes tempos históricos da educação brasileira.

A partir dessa consideração, passamos a observar as apropriações ofertadas às legislações no tocante às análises sobre os objetos eleitos. A recorrência à legislação, inicialmente, se apresenta como forma de resgate do processo constitutivo do ensino secundário nas distintas regiões do País.

Até o ano de 1930, o CBM manteve curso particular. Só em 1931 passou [a] estabelecimento de ensino secundário reconhecido, quando obteve inspeção preliminar, sendo-lhe concedida a inspeção permanente pelo Decreto no 775 de 27 de abril de 1936 [...] o CBM "é de fato agora, um colégio. Foi assinado um decreto pelo Exmo. Sr. Presidente da República (...) Eurico Gaspar Dutra no dia 09 de abril dêste ano [1946]". O decreto informado autorizava o CBM a funcionar como Colégio: "O artigo $2^{\circ}$ do decreto reza: 'A denominação do Estabelecimento de ensino secundário de que trata o artigo anterior passa a ser COLÉGIO BATISTA MINEIRO"'. (SANTOS, 2010, p. 72 e 132, grifos nosso).

[...] a fim de dar cumprimento à Portaria № 180/62 da Secretaria de Educação, Cultura e Saúde do Estado tendo em vista a Lei das Diretrizes e Bases da Educação resolve pôr em vigor neste Estabelecimento a referida Portaria a partir do dia 26 do corrente, $2^{\underline{a}}$ feira. Pela mesma são suprimidos do currículo: a) Latim do $1^{\circ}$ ciclo, com opção no $3^{\circ}$ colegial; Inglês da $2^{\underline{a}}$ série $\left(1^{\circ}\right.$ ciclo) com redução das aulas na $3^{a}$ 
e $4^{\mathrm{a}}$ séries e curso colegial, Francês da $3^{\mathrm{a}}$ e $4^{\mathrm{a}}$ séries ( $1^{0}$ ciclo) e do colegial, desenho das 2 primeiras séries ( $1^{\circ}$ ciclo) [...]. (PORTARIA no 8/62, de 24 de março de 1962, Livro Portarias, 1957 apud Oliveira, 2009, p. 23, grifos nosso).

Buscando entender tal apropriação, passamos a indagar as estruturas e os processos, que determinam o alcance da legislação no processo de reconstituição histórica. Dito de outro modo, mais do que uma história política, o estudo das transformações desencadeadas na educação e, por que não dizer, na sociedade, por meio das legislações para/do ensino secundário, permite apreender tensões, que informam sobre os impactos causados na vida individual e coletiva, sobre a cultura, a formação humana e a boa educação, neste caso, em duas distintas regiões do País.

No que se refere à Minas Gerais, particularmente, o estabelecimento de normas concernentes à organização do ensino secundário, encontra sentidos e significados que afeta diretamente as cidades e os sujeitos, divulgando e legitimando modos de vida, que ressoam diretamente na cultura.

No âmbito nacional, foram se instalando pelo Brasil diversas Congregações religiosas de origem europeia, desde a segunda metade do século XIX, promovendo uma educação de valores culturais europeus, primando pela ordem e pela disciplina. (SANTOS, 2010, p. 86, grifos nossos).

O repertório utilizado na disciplina, recomendado para todas as instituições de ensino do país era baseado, principalmente, no folclore nacional, objetivando assim a preservação dos valores culturais do povo brasileiro. (NEIVA, 2008, p. 59, grifos nossos).

As proposições contidas nessas análises, acerca das instituições e/ou disciplinas escolares, são vistas, também, como ato ou efeito de tornar escolar a vida social, submetendo os sujeitos, seus conhecimentos, seus valores e suas condutas aos imperativos da escola.

Recorremos à Thompson (1981), por entendermos que tal submetimento impõe limites e, em última instância, estabelece condições para a ação dos sujeitos, isto é,

[...] as pessoas experimentam sua experiência como sentimento e lidam com esses sentimentos na cultura, como normas, obrigações familiares e de parentesco, e reciprocidade, como valores ou (através de formas mais elaboradas) na arte ou nas convicções religiosas. Essa metade da cultura (e é uma metade completa) pode ser descrita como consciência afetiva e moral. (THOMPSON, 1981, p. 189).

Os vestígios do ato, ou efeito de tornar escolar, são identificados, na análise de dois momentos distintos de duas disciplinas escolares, Latim e Francês, no Colégio CampoGrandense.

[...] em cada período da sua história no locus da pesquisa, a disciplina Latim configurou-se de acordo com: A) fatores internos, ou seja, conforme a natureza dos conhecimentos sobre a língua latina então disponíveis, pelo nível de desenvolvimento em que se encontravam esses conhecimentos, pela formação dos profissionais atuantes na área; B) fatores externos, ou seja, as condições sociais, econômicas e culturais que determinavam a escola e o ensino, referentes, por exemplo: I) aos grupos sociais que tinham acesso às aulas; às expectativas, aos interesses e aos objetivos de tais grupos e da sociedade em geral em relação à escola $\mathrm{e}$ ao que se deve ensinar e aprender nela a respeito da língua latina; II) ao regime político em que a escola estava inserida, bem como o 
ensino do Latim, além da estrutura do sistema educacional. (BRAGA, 2005, p. $92-$ 93, grifos nossos).

[...] a disciplina Francês cumpria um papel elitizante voltado para grupos sociais específicos, que podiam não somente chegar e concluir um ensino secundário, como também tentar o ensino superior. (OLIVEIRA, 2009, p. 204, grifos nossos).

Esses vestígios também dão conta de elementos intrínsecos da forma e cultura escolares, pois além de identificarem as condutas e os conhecimentos mobilizados pelos sujeitos, permitem questões acerca das práticas, que regulam a vida social, em decorrência do acesso aos conhecimentos escolares.

A produção desses elementos, contudo, serve para que percebamos que não é possível pensar determinado processo de escolarização separado da importância e legitimidade, que alcança no interior das experiências dos sujeitos. E, neste sentido, o processo de formação, ou por que não dizer, de autoformação, oferecido/construído aos/pelos sujeitos, pode resultar independente da intencionalidade.

A formação, assim, parece mobilizada para o atendimento dos interesses de uma classe, contudo, os sujeitos experimentam as situações e as relações de aprendizado, determinados por necessidades e interesses que são, ou já foram 'tratados' pela experiência em sua consciência e cultura.

Diante disso, longe de qualquer idealização, a formação ofertada pelo ensino secundário, dependente do imaginário social criado em torno das instituições escolares e/ou da importância das disciplinas, é vivida e alimentada pela vida material e as relações materiais em que os sujeitos estão imersos.

Tal imersão remete-nos à premissa de que a cultura deve ser aprendida, e esta mesma cultura, também, oferece aos sujeitos as sensibilidades e as habilidades para sua inserção no mundo escolar.

As escolas, portanto, produzem ou processam, tanto o conhecimento quanto as pessoas. Em essência, o conhecimento formal e informal é utilizado como um filtro complexo para produzir ou processar pessoal, em geral por classes; e, ao mesmo tempo, diferentes aptidões e valores são ensinados a diferentes populações, frequentemente também de acordo com a classe (e o sexo e a raça). Na verdade, para essa tradição mais crítica, as escolas recriam de maneira latente disparidades culturais e econômicas, embora isso não seja, certamente, o que a maior parte das escolas pretenda. (APPLE, 2006, p. 68, grifo do autor).

Exemplo disso apreende-se nas fontes estudadas, quando os autores mencionam os dispositivos que as instituições utilizam na configuração da boa educação, vejamos:

A disciplina rígida e a preocupação com a formação moral de seus frequentadores eram fator diferencial dos colégios católicos, tornando-os de grande atrativo para as famílias abastadas, pois seu elevado nível cultural foi a razão principal da obtenção de seu prestígio perante a sociedade brasileira. (SANTOS, 2010, p. 88).

Observa-se, então, a coexistência de um currículo para o ensino secundário com disciplinas humanísticas e disciplinas científicas; aquelas, porém, comprometidas na formação de uma cultura geral e moral do jovem e não necessariamente com a finalidade de prepará-lo para a vida prática e profissional. (OLIVEIRA, 2005, p. 37).

Para Goodson (2005), a explicação acerca das matérias escolares, métodos e 
cursos de estudo constituiu na história do currículo, de um lado, mecanismo para designar e diferenciar estudantes e, de outro, ofertou uma pista para analisar as relações complexas entre escola e sociedade. Esta última, ancorada na configuração de como escolas tanto refletem como refratam definições da sociedade sobre conhecimento culturalmente válido em formas que desafiam os modelos simplistas da teoria de reprodução.

Neste quadro, a boa educação, alcançada com/pela forma constitutiva do processo de curricularização das ações de formação nas instituições escolares, incorre não somente na questão dos limites da experiência, mas na maneira de alcança-la, ou produzi-la.

A experiência surge espontaneamente no ser social, mas não surge sem pensamento. Surge porque homens e mulheres (e não apenas filósofos) são racionais, e refletem sobre o que acontece a eles e ao seu mundo. (THOMPSON, 1981, p. 16).

Braga (2005) evidencia essa questão ao registrar, que "numa disciplina, misturamse exposição de conteúdos e formação do espírito" (p. 40). Já Santos (2010) corrobora essa análise, ao considerar que "as instituições de ensino de cunho religioso, se fundamentavam nos princípios de uma disciplina severa, de autoridade e obediência”. (p. 100).

Ao exporem tal leitura, os autores advogam a disciplina, aqui entendida na perspectiva de conformação de comportamentos, como componente indissociável das análises sobre a boa educação. Em outras palavras, a boa formação, e sua consciência por parte dos sujeitos, concebidas como derivação do processo de formação, que em última instância não deixa de ser cultural. O comportamento "adequado", neste sentido, passa a ser um dos responsáveis diretos pela formação humana, que no universo escolar, de instituições e ações coletivas alicerçadas em uma base cultural, acaba por colocar em segundo plano, as práticas individuais dos sujeitos cultos, formados solidamente e bemeducados.

\section{Notas finais (uma construção ainda em processo)}

Do ponto de vista metodológico, as áreas de comparação traduzem não apenas a materialidade das noções eleitas, mas também os mercados simbólicos que descreve, interpreta e localiza uma configuração para o ensino secundário. Nesse mercado as diferenças de incorporação e instrumentalidade das noções em análise, determinam que as fontes incorrem em um sentido de apropriação do conjunto legal, nomeado pelo entendimento da educação secundária como direito de todos, tornando-o um espaço gerador e fomentador da cultura, da formação humana e da boa educação, como práticas que marcam tão somente a qualidade social.

Se tivermos claro que a cultura, a formação humana e a boa educação, mais do que noções, constituem-se em conteúdos a serem aprendidos no ensino secundário, e estes mesmos conteúdos, também, passam à condição de categorias simbólicas de classificação, que materializa a qualidade deste ensino, então os processos de apropriação desses conteúdos envolvem, uma ação mais ou menos deliberada de suporte para um tipo de ensino de formação básica da elite.

Do mesmo modo, a análise da regionalidade do ensino secundário, aqui delineada, envolve um conjunto de experiências que, ao longo desse espaço e tempo, tem as instituições escolares como interlocutoras da cultura, da formação humana e da boa 
educação, que articuladas aos interesses da elite, não se convertem como possível instrumento de democratização do ensino, mas, sim, em escolas elitistas.

Dessa forma, os sentidos da apropriação se dão à medida da designação. Medida essa, que de um lado, parece não ser determinada por uma história local e, sim, por uma história, que coloca à sombra e à margem os possíveis elementos de cada um dos jogos, que constitui o ensino secundário nos movimentos das distintas vidas sociais, sul de Mato Grosso (Campo Grande) e Minas Gerais (Belo Horizonte). De outro, como diria Thompson (1984), a "radicalidade da gente comum" não se traduz no desenho do coletivo, tendendo a edificar um padrão de análise, que compreende o conjunto criado por outros jogadores, àqueles da história já contada do ensino secundário.

Sendo assim, apreender por comparação a história dos ensinos secundários em duas regiões, ou cidades do país, trouxe mostras pouco significativas do relevo das singularidades regionais ou locais de um determinado processo histórico, seus nexos e intercâmbios com a história da educação do ensino secundário, já contada. Talvez essas singularidades ampliassem as possíveis mudanças e as necessárias intervenções nas tradições historiográficas daquela história, justamente porque seriam construídas (e reconstruídas) nas experiências e nas práticas locais. Por isso mesmo, pensar outra configuração seria buscar a transformação e a representação social do espaço local, tratando das expressões e da multiplicidade, mais do que diferenças e semelhanças.

\section{Referências}

APPLE, Michael. Ideologia e currículo. Porto Alegre, RS: Artmed, 2006.

BRAGA, Horácio dos Santos. O ensino de Latim na Escola Maria Constança Barros Machado como reflexo da história da disciplina no Brasil (1939-1971). 2005.

Dissertação (PPGE - Curso de Mestrado) - Campo Grande, Universidade Federal de Mato Grosso do Sul, 2005.

BRASIL. Decreto $n^{\circ} 19.890$, de 18 de abril de 1931. Dispõe sobre a organização do ensino secundário. In: VIEIRA, S. L. et al. Leis de reforma da educação no Brasil: império e república. v. 2. Brasília: INEP, 2008. p. 108-118.

Decreto no 21.241 de 04 de abril de 1932. In: ROMANELLI, Otaíza de Oliveira. História da educação no Brasil (1930-1973). 18 ed. Petrópolis: Vozes, 1996. p. 136-139.

Lei n. 4024, de 20 de dezembro de 1961. Fixa as Diretrizes e Bases da Educação Nacional. In: Documenta n.1, Rio de Janeiro, março 1962.

Reforma Capanema. Decreto no 4.244 de 09 de abril de 1942. 1942. Disponível

em:

<http://www.histedbr.fe.unicamp.br/navegando/fontes_escritas/5_Gov_Vargas/decretolei\%204.244-1942\%20reforma\%20capanema-ensino\%20secund\%E1 rio.htm>. Acesso em: 14 ago. 2015.

DEPAEPE, Marc; SIMON, Franky. Sobre el treball amb fonts: consideracions des del taller sobre la història de l'educació. Educació i Història: Revista d'Història de l'Educació, n. 15, p. 99-122, gen./jun. 2010.

DUBET, François. O que é uma escola justa? Cadernos de Pesquisa, São Paulo, v. 34, n. 123, p. 539-555, set./dez. 2004.

ELIAS, Norbert. Introdução à sociologia. Braga: Edições 70, 1980. 
FENDLER, Lyn. There Are No Independent Variables in History. In: POPKEWITZ, Thomas S. (Org.). Revisioning the History of Education Transnational Perspectives on its Questions, Methods, and Knowledge. New York: Palgrave Macmillan, 2013. p. 223-244. GONÇALVES NETO, Wenceslau. Cultura escolar e legislação e Minas Gerais: o município de Uberabinha no início da República. In: YAZBECK, D. C.; ROCHA, M. B. M. da. Cultura e história da educação: intelectuais, legislação, cultura escolar e imprensa. Juiz de Fora: Editora UFJF, 2009. p. 69-102.

GOODSON, Ivor. Currículo: teoria e história. Petrópolis (RJ): Vozes, 2005.

NEIVA, Ismael Krishna de Andrade. Educação Musical Escolar: o canto orfeônico na escola normal de Belo Horizonte (1934-1971). 2008. Dissertação (Mestrado em Educação) - Faculdade de Educação da UFMG, Belo Horizonte, 2008.

NUNES, Clarice. O "velho" e "bom" ensino secundário: momentos decisivos. Revista Brasileira de Educação, São Paulo, ANPED, n. 14, p. 35-60, 2000.

OLIVEIRA. Stella Sanches. A história da disciplina escolar francês no Colégio Estadual Campograndense (1942-1962). 2009. Dissertação (PPGE - Curso de Mestrado) -Universidade Federal de Mato Grosso do Sul, Campo Grande, 2009.

QUEIROZ, Paulo Roberto Cimó. Condições econômicas do sul de Mato Grosso no início do século XX. Fronteiras, Campo Grande, v. 1, n. 2, p. 113-136, 1997.

RAWLS, Jonh. Justiça e Democracia. São Paulo: Martins Fontes, 2002.

SANTOS, Hércules Pimenta dos. Católicos e Protestantes: escolas confessionais fundadas por missionários estrangeiros, Belo Horizonte - MG (1900-1950). 2010. Dissertação (Mestrado em Educação) - Faculdade de Educação da UFMG, Belo Horizonte, 2010.

SILVA, Fabiany Cássia Tavares. Observatório de Cultura Escolar (9): estudo históricocomparado da produção de conhecimento sobre o ensino secundário. UFMS, CNPQ Edital de Ciências Humanas, 2013.

Dos Estudos Comparados à Escrita Histórico-Social do Currículo:

documentos curriculares como fontes. Mimeo: Pesquisa Pós-doutorado Sênior, CNPQ, 2014.

SOUZA, Rosa Fátima de. História da organização do trabalho escolar e do currículo no século XX: ensino primário e secundário no Brasil. São Paulo: Cortez, 2008.

SCHWARTZMAN, Simon.; BOMENY, Helena Maria Bousquet.; COSTA, Vanda Maria Ribeiro. Tempos de Capanema. São Paulo: Paz e Terra; Fundação Getúlio Vargas, 2000.

THOMPSON, Edward Palmer. A miséria da teoria. Rio de Janeiro: Zahar, 1981.

Tradición, revuelta y consciencia de clase. Barcelona: Crítica; Grijalbo, 1984.

WARDE, Mirian Jorge. Investigações acerca da escola no espaço-tempo da cultura escolar. In: SILVA, F. C. T.; PEREIRA, M. V. M. Observatório de Cultura Escolar: estudos sobre escola, currículo e cultura escolar. Campo Grande: Editora UFMS, 2013. p. 33-50. 
FABIANY DE CÁSSIA TAVARES SILVA é Pós-doutora do Programa de Pós-graduação em Educação, Unifesp. Doutora em Educação pela Pontifícia Universidade Católica de São Paulo (PUC-SP), professora-pesquisadora do Programa de Pós-graduação em Educação da Universidade Federal de Mato Grosso do Sul (UFMS), Líder do Grupo de Estudos e Pesquisas Observatório de Cultura Escolar (OCE), Bolsista Produtividade em pesquisa - CNPQ.

Endereço: Rua Guarujá, 229 - Vila Sobrinho- 79110 - Campo Grande/MS - Brasil.

E-mail: fabiany.tavares@ufms.br

MAURINICE EVARISTO WENCESLAU é Doutora (2005) e Mestre (1997) em Direito das Relações Sociais pela Pontifícia Universidade Católica de São Paulo (PUC/SP). Professora adjunta e pesquisadora da Universidade Federal de Mato Grosso do Sul (UFMS), atua na Graduação e no Programa 213 de Pós-Graduação em Direitos Humanos (Curso de Mestrado). Pesquisadora do Observatório de Cultura Escolar e Líder do Laboratório de Estudos e Pesquisa em Direito Difuso.

Endereço: Rua Hanna Abdulahad, 217, Bloco J, Ap. 1 - Jardim Paradiso - 79117-008 - Campo Grande/MS - Brasil.

E-mail: maurinice@uol.com.br

Recebido em 18 de abril de 2016.

Aceito em 18 de maio de 2017. 